\title{
The Effect of Warm Water Soaking Therapy on Sleep Quality in Third Trimester Pregnant Women
}

\section{Yayat Suryati* and Fitri Solihat}

Department of Nursing, Sekolah Tinggi IImu Kesehatan Jenederal Achmad Yani, Cimahi, Indonesia

\section{ORCID}

Yayat Suryati: https://orcid.org/0000-0002-7279-9857

Corresponding Author: Yayat Suryati; email:

suryatiyayat.2019@gmail.com

Published: 7 February 2022

Publishing services provided by

Knowledge E

(c) Yayat Suryati and Fitri

Solihat. This article is distributed under the terms of the

commons Attribution License,

which permits unrestricted use and redistribution provided that the original author and source are credited.

Selection and Peer-review under the responsibility of the IVCN Conference Committee.

\begin{abstract}
One of the health problems commonly experienced by pregnant women is issues with sleep quality in the third trimester. In America as many as $78 \%$ of women have more sleep disturbances during pregnancy compared to other times. One of the non-pharmacological ways to manage bad sleep quality is soaking the feet in warm water. The purpose of this study was to determine the effect of warm water foot therapy on the sleep quality of third trimester pregnant women. This was a quasi-experimental study with a pretest-posttest design and a control group. The sample consisted of 24 respondents, 12 of whom were divided into the intervention group and 12 into the control group. Data analysis was carried out in two stages, namely univariate and bivariate by using dependent and independent $t$-tests. The results showed that there was a significant difference in the quality of sleep in third trimester pregnant women in the Cigugur Central Health Center in Cimahi City before and after their feet were treated with warm water $(p<0.001)$. It is therefore recommended that third trimester pregnant women who have sleep quality problems soak their feet in warm water before going to bed.
\end{abstract}

Keywords: pregnancy, sleep quality, therapy soak warm water

\section{Introduction}

Pregnancy is a continuous chain and consists of release of the ovum or ovulation, migration of spermatozoa and ova, conception and growth of the zygote, nidation (implantation) in the uterus, placental formation and growth and development of the conception to the term [1]. Pregnancy is divided into 3 trimesters, namely trimester I starting from conception to 3 months, trimester II from the 4th month to the 6th month, trimester III from the 7th to 9th month [2]. Pregnant women will experience psychological or physical changes, especially in third trimester pregnant women. Usually, third trimester pregnant women often experience sleep disorders due to psychological and physical changes [3].

Complaints about disturbed sleep patterns in the third trimester of pregnancy can G OPEN ACCESS 
shortness of breath, the urge to urinate continuously and the fetus has begun to grow enlarged [4]. Supported by [5] research that sleep patterns of third trimester pregnant women will experience changes from normal sleep patterns in women. This can be seen from the description of the sleep parameters of trimester III pregnant women, namely the number of frequency of waking up at night $(51 \%)$ has increased because during the third trimester of pregnancy there are physical changes such as frequent urination, when lying down the breast feels painful, and often complains back pain so that the quality of his sleep disturbed.

Sleep quality is a person's ability to be able to maintain a state of sleep and to get good REM (Rapid Eye Movement) and NREM (Non Rapid Eye Movement) sleep stages [6]. Adequate quality of sleep can maintain the health of the mother during pregnancy and the fetus in her womb. Because sleep is one of the basic human needs that must be met every day and a biological process that is common to everyone [6].

According to the National Institutes of Health quoted by the National Sleep Foundation, based on data from the National Sleep Foundation's 1998 Women and Sleep poll, as many as $78 \%$ reported that women in America had more disturbed sleep patterns during pregnancy compared to other times. Usually in first trimester and third trimester pregnant women mostly complain and feel very tired.

Research according to [5] in Medan Marelan found that sleep quality and sleep patterns of third trimester pregnant women were poor of 41 pregnant women (63\%) and good sleep quality (15\%). Because, physiological and psychological changes experienced by pregnant women and the results of this study recommend to provide and optimize good sleep patterns in third trimester pregnant women. Then, according to a study conducted by [7] at the RBC Sinergi Foundation Bandung Primary Clinic, said that of the 32 respondents in third trimester pregnant women experiencing poor sleep quality because the average score (PSQI) $>5$ was 10.12. This is due to frequent waking up at night, frequent urination, back pain. Then, according to a research by [8] in Surabaya, it was found that there was a percentage of pregnant women who had poor sleep quality, namely 19 pregnant women (52.8\%) and pregnant women had good sleep quality, as many as 17 pregnant women (47, 2\%). This is the highest proportion of sleep quality for third trimester pregnant women, which is having poor sleep quality.

Poor sleep quality in pregnant women can interfere with their health such as feeling less focused, unable to concentrate properly, easily tired, not feeling well, lazy when working, daily activities will decrease and emotional will also increase [3]. Decreased duration of sleep can cause depression and stress so that it can affect the fetus in the 
womb, namely mild stress that can increase fetal heart rate, then severe and prolonged stress will also cause the fetus to become hyperactive [3]. This requires handling.

Reducing disruption of sleep quality there are several ways, namely positive thinking, light exercise, relaxation therapy and hydrotherapy [9]. Hydrotherapy is one method of treatment using water to treat or alleviate painful conditions. One form of hydrotherapy is to soak feet using warm water. Soak feet in warm water is a condition where the feet will be in direct contact with warm water with a temperature of $380 \mathrm{C}-390 \mathrm{C}$. Warm water can cause a feeling of comfort in the muscles because there is a decrease in muscle tension that causes blood vessels to become wide and stretching of muscle cells [9].

The advantage of this therapy is that it can prevent colds or fever, improve fertility, cure fatigue, increase immunity, increase body energy, increase the sofartifik effect (feeling of wanting to sleep) and help smooth blood circulation. [9]. Supported by a study by [10] there is the effect of hydrotherapy soaking warm water feet on blood pressure levels in elderly people with hypertension in DepokAmbarketawangGamping Village, Sleman Yogyakarta, the research results showed before hydrotherapy soaking warm water foot systolic and diastolic blood pressure on average $78.9 \%$ moderate classification. The results after soaking the foot of warm water systolic and diastolic blood pressure averaged $52.3 \%$ normal classification.

According to the Cimahi City Health Office in 2018 the highest number of third trimester pregnant women visits was the Central Cigugur Health Center with a total of 1,350, and the second Cibereum Health Center was 1,294 third trimester pregnant women [11]. Therefore, researchers will conduct research at the Cigugur Middle Health Center in Cimahi City because the visit of third trimester pregnant women is very high, to determine the quality of sleep in third trimester pregnant women.

The results of a preliminary study conducted by researchers on 11 and 15 February 2019 through interviews with 10 third trimester pregnant women at Cigugur Central Health Center, Cimahi City, the results showed that 9 people said they had difficulty maintaining sleep, often waking up at night and waking up earlier due to discomfort felt such as frequent urination at night, restlessness, back pain, shortness of breath. Then, 1 person said that he could still maintain his sleep.

Based on the description above, the researchers intend to submit the title of the thesis "The Effect of Therapeutic Warm Water Soak on Feet on Sleep Quality of Third Trimester Pregnant Women in Cigugur Public Health Center, Cimahi City" 


\section{Methods}

The design used in this study was a quasi experimental pretest-posttest with control group.Sampling using non-probablity sampling with a purposive sampling technique design, namely third trimester pregnant women in the working area of Cigugur Middle Health Center Cimahi City who experience sleep disorders. The sample size used the formula for the 2010 calculation. Obtained a sample of 11 people, for the treatment and control group to be 22 respondents. Increase the number of samples by $10 \%$ to avoid dropout samples, bringing the total sample to 24 people.

Inclution criterias were the third trimester of pregnancy ( 28 weeks - 42 weeks), third trimester pregnant women who experience poor sleep quality such as waking up at night more than 3 times, living in Cigugur Tengah Cimahi City, able to communicate well, willing to work together in research and follow the activities from the beginning to the end of the study, willing to be respondents. On the other side, exclution criterias were pregnancy $<6$ months, first pregnancy with age less than 16 years, pregnancy over the age of 35 years, had a miscarriage or premature childbirth, pregnancy with hypertension, diabetes, hypertension, heart disease, diabetes, bleeding.

This research instrument was used the Pittsburgh Sleep Quality Index (PSQI) questionnaire to determine sleep quality [12]. The tool the researcher used was standard because it had a reliability coefficient (Cronbach's Alpha) of 0.38 and internal consistency. PSQI was developed to provide a valid measure and have a standard sleep quality value. The Pittsburgh Sleep Quality Index (PSQI) score starts from 0 to 21 . The results of sleep quality are said to be good sleep if $0=$ score $\leq 5$ and said sleep quality is poor if $1=$ score $>5$.

The data collection process was carried out at Cigugur Tengah Health Center in Cimahi City in RW 19 and RW 07 for 3 weeks, where the first day researchers randomized respondents to be visited by their homes, on the first week researchers visited 12 respondents for the treatment group which was divided into 2 namely the first week 6 people and the second week 6 people. Then, in week 3 the researcher came to 12 respondents who had been randomly selected by the researcher.

The bivariate analysis used is the $t$ test analysis by comparing the differences in the two groups of means or samples whether there is a difference or not. $T$ test has normal distributed data requirements. Before the $t$ test is done, first do a Shapiro Wilk test to find out whether the data is normally distributed or not. The Shapiro Wilk test requirement is if Pvalue $\geq 0.05$ then the data is said to have normal distribution, whereas if Pvalue $\leq$ 0.05 then the data distribution is said to be abnormal. If the data normality test results 
TABLE 1: Average Sleep Quality of Pregnant Women Trimester III Before Given Warm Water Soak Therapy in the Foot Against the Intervention and Control Group. $(\mathrm{N}=12)$

\begin{tabular}{l|l|l|l|l|}
\hline Group & $\mathbf{N}$ & Mean & SD & Min-Max \\
\hline Intervention & 12 & 10,33 & 1,557 & $8-13$ \\
\hline Control & 12 & 11,67 & 1,923 & $9-15$ \\
\hline
\end{tabular}

TABLE 2: Average Sleep Quality of Pregnant Women Trimester III After Given Warm Water Soak Therapy in the Foot Against the Intervention and Control Group. $(\mathrm{N}=12)$

\begin{tabular}{l|l|l|l|l|}
\hline Group & N & Mean & SD & Min-Max \\
\hline Intervention & 12 & 5,25 & 1,557 & $8-13$ \\
\hline Control & 12 & 11,58 & 1,881 & $9-15$ \\
\hline
\end{tabular}

are not normal, then the non-parametric test is carried out, namely Mann-Whitney or Wilcoxon.

The results of the Shapiro-Wilk test in the intervention group before and after were 0.348 and 0.134 (Pvalue $\geq 0.05$ ) while in the control group before and after the significance values of 0.300 and 0.238 (Pvalue $\geq 0.05$ ) were obtained. This shows that the data are normally distributed, so that in this study analyzed using the dependent $t$ test and independent $t$ test.

\section{Results}

The average quality of sleep of third trimester pregnant women before being given warm water soak therapy in the feet of the intervention and control group at Cigugur Central Health Center, Cimahi City.

Based on table 1, the average sleep quality of third trimester pregnant women is obtained before giving warm water soak therapy to the feet of the intervention group, 10.33 (Poor) and the control group, 11.67 (Poor).

\subsection{The average quality of sleep of third trimester pregnant women after being given warm water soak therapy in the feet of the intervention and control group at Cigugur Central Health Cen- ter, Cimahi City.}

Based on table 2, it is found that the average quality of sleep of third trimester pregnant women after being given warm water soak therapy in the feet of the intervention group is 5.25 (Poor) and the control group is 11.58 (Poor). 
TABLE 3: Difference in Average Sleep Quality of Trimester III Pregnant Women After Therapeutic Warm Water Warming on the Legs of Both Groups. $(\mathrm{N}=12)$

\begin{tabular}{l|l|l|l|l|}
\hline Group & $\mathbf{N}$ & Mean & SD & $\mathbf{P}_{\text {value }}$ \\
\hline Intervention & 12 & 5,25 & 0,965 & \\
\hline Control & 12 & 11,58 & 1,881 \\
\hline
\end{tabular}

The difference in the average quality of sleep of third trimester pregnant women after being given warm water soak therapy in the legs of the two groups at the Cigugur Public Health Center in Cimahi City.

Based on Table 3, it is known that the average score of sleep quality in the third trimester of posttest pregnant women in the intervention group was 5.25 and the average score of sleep quality of the third trimester posttest pregnant women in the control group was 11.58. There was a mean difference in the posttest in both groups of 6.33. The statistical test results obtained Pvalue $0,000(\alpha \leq 0.05)$ it can be concluded that there is a difference between the sleep quality of third trimester pregnant women in the intervention group and the control group.

\section{Discussion}

The average quality of sleep of third trimester pregnant women before being given warm water soak therapy in the feet of the intervention and control group at Cigugur Central Health Cnter, Cimahi City.

Based on table 1 the results of univariate analysis of PSQI scores in third trimester pregnant women before being given warm water soak therapy in the foot of the intervention and control groups showed that as many as 24 (100.0\%) third trimester pregnant women experience poor sleep quality with an average value the sleep quality score of trimester III pregnant women was the intervention group 10.17 (Poor) and the control group 11.83 (Poor). This shows that third trimester pregnant women both in the intervention and control groups had poor sleep quality because of PSQI score $\geq$ 5.This is consistent with research conducted by [13] at the Jetis Public Health Center in Yogyakarta City, saying that sleep disturbances begin early in pregnancy and get worse at the end of pregnancy. The results of this study indicate that poor sleep quality in first trimester pregnant women $59.1 \%$, second trimester $64.3 \%$ and third trimester $65.5 \%$.

The results of this study are supported by research [14] said that sleep disorders can be felt because they feel anxious, worried, and physical discomfort that is usually felt by third trimester pregnant women. This is one of the awareness of the mother that her pregnancy is nearing the end, and will cause a sense of concern about the 
process of labor that is not normal, feeling anxious about the baby in the womb will be born normally or not. Physical discomfort is related to changes in body shape such as lower back pain, and not feeling well. In this condition it will cause further feelings of anxiety and discomfort until the mother feels more difficult to sleep.According to the Department of Anesthesiology, Yale University School of Medicine, 950 pregnant women were surveyed about low back pain during pregnancy, how it affected daily life and how their health care workers deal with pain. The study showed that 645 respondents reported back pain during pregnancy and the majority stated that it caused sleep disturbance. These aches and pains can be related to ligaments between pelvic bone softening (due to the influence of relaxin hormone on ligaments) and sagging joints in preparation for birth. The weight of the fetus in the womb also affects body posture so that most pregnant women are uncomfortable when walking, sitting, and sleeping (National Sleep Foundation, 2017). Another factor that can cause sleep quality in trimester III pregnant women is shortness of breath.

According to [14] shortness of breath can be caused due to physical changes that are the influence of hormones. Then shortness of breath is also caused by fetal growth and pushing the diaphragm upward, the shape and size of the chest cavity also changes but does not become smaller. The capacity of the lungs to inspire air remains the same as before pregnancy. Tidal volume, ventilation volume per minute, and the need for 02 increase. this is due to a change in the shape of the thoracic cavity and the frequency of breathing increases, about $60 \%$ of pregnant women complain of shortness of breath. Then, according to research by [7]shortness of breath caused by the condition of the uterus that is getting bigger and pressing on the lungs. Pregnant women also find it difficult to find a comfortable sleeping position, and breathing activities also require hard work so that the problem will interfere with the quality of mother's sleep.Poor sleep quality in pregnant women can interfere with their health such as feeling less focused, unable to concentrate properly, easily tired, not feeling well, lazy when working, daily activities will decrease and emotional will also increase [3]. Then, the reduced duration of sleep can cause depression and stress so that it can affect the fetus in the womb, namely mild stress that can increase fetal heart rate, then severe and prolonged stress will also cause the fetus to become hyperactive [3]. Then, there are other factors that can cause the mother's quality of sleep to be disrupted, which is frequent urination at night.According to [8] factors that influence pregnant women often urinate at night because of the enlargement of the uterus and fetus that will continue to push the intestine towards the side. One thing that pregnant women can do is to drink a lot at least eight $(250 \mathrm{ml})$ of glass 8 times a day. Mother is recommended to reduce drinking 
water intake at night so that her sleep is not disturbed because of frequent urination at night.

The average quality of sleep of third trimester pregnant women after being given warm water soak therapy in the feet of the intervention and control group at Cigugur Central Health Center, Cimahi City.

Based on table 2 the results of univariate analysis of PSQI scores in third trimester pregnant women after being given warm water soak therapy in the foot of the intervention group showed that as many as 12 (100.0\%) with a percentage of 7 (58.3\%) third trimester pregnant women experiencing sleep quality a good and $5(41.7 \%)$ pregnant women who experienced poor sleep quality with an average score of sleep quality during the third trimester of pregnant women after being given therapy 5.25 (Poor). The control group showed that out of 12 respondents (100.0\%) third trimester pregnant women experienced poor sleep quality with an average score of sleep quality for trimester III pregnant women after being controlled for 7 days, 11.58 (poor).The results of this study are supported by the study of [9] . There is an effect of soaking feet with warm water on the level of anxiety in third trimester pregnant women in Puskesmas Pegadon Kendal. The results of this study indicate that there is an effect of soaking feet with warm water on the level of anxiety in third trimester pregnant women in Kendal pegadon health center with a $p$ value of $0,000<0.05$.

According to the research of [15] there is an effect of warm water soak therapy in the feet of elderly insomnia with insomnia results in pretest before warm water soak therapy in the feet in the village of Angges, West Tahuna sub-district ie a small proportion of elderly people experience insomnia 11-19 ( no complaints of insomnia) and most experienced 20-27 (mild insomnia) and 28-36 (severe insomnia). Posttest insomnia after warm water soak therapy in the feet, most of the elderly are insomnia 11-19 (no complaints), insomnia 20-27 (mild insomnia) and a small portion experience insomnia 28-36 (severe insomnia). Insomnia can only be felt by each individual.Improved sleep quality due to soaking warm water on the feet is a relaxation response that suppresses sympathetic nerves. This condition is caused by parasympathetic nerve activity which is more active and active [16]. Warm water can cause a feeling of comfort in the muscles because there is a decrease in muscle tension which causes blood vessels to become wide and stretching of muscle cells [9].

Sleep quality is the ability of a person to be able to maintain a state of sleep and to get good REM (Rapid Eye Movement) and NREM (Non Rapid Eye Movement) sleep stages [6]. Adequate sleep quality can maintain the health of the mother during pregnancy and the fetus in her womb. Good sleep can not only be seen from the number of 
hours of sleep, but from the quality of sleep. Not a few people complained of being dissatisfied with their sleep, for example, often waking up when they were sleeping, not soundly so they were not fresh when they woke up even though they slept for a long time. Whereas people who have good sleep quality will feel satisfied with their sleep and feel refreshed when they wake up and their activities during the day will not be disturbed even though the number of hours of sleep is not long [17]. In the results of studies that have been conducted by researchers showed the average sleep quality score in the intervention group of third trimester pregnant women decreased between before and after the intervention. The smaller the sleep quality score indicates that the quality of sleep is getting better, so it can be concluded that the intervention of soaking feet with warm water can improve sleep quality. The improvement in the quality of sleep of third trimester pregnant women in this study was due to the third trimester pregnant women experiencing good changes in sleep time, sleeping position and other factors. It is known that the sleep time of third trimester pregnant women is increased where the start of sleep of third trimester pregnant women on average at 21.00 and woke up at 05.00 , so the sleep time of pregnant women trimester III an average of $>6$ hours.

The difference in the average quality of sleep of third trimester pregnant women after being given warm water soak therapy in the legs of the two groups at the Cigugur Public Health Center in Cimahi City.

The difference in the mean PSQI score of trimester III pregnant women after being given therapy in the intervention group using the dependent $t$ test was 5.083 with a $P$ value of 0,000 (Pvalue $\leq 0.05$ ). can improve sleep.In the third trimester pregnant women who do warm water soak therapy on the feet before going to sleep this is very useful in reducing things that cause pregnant women to experience sleep disorders such as leg cramps, anxiety, and back pain. Warm water can cause a feeling of comfort in the muscles because there is a decrease in muscle tension which causes blood vessels to become wide and stretching of muscle cells [9]. This research is supported by research [9] said that the benefits of warm water soak therapy in this leg can be to prevent flu or fever, improve fertility, cure fatigue, increase immunity, increase body energy, increase sofartifik effect ( feeling of wanting to sleep) and helps smooth blood circulation.

Soaking warm water on the feet can create a relaxed state that will increase serotonin production and then convert to melatonin so that drowsiness arises and maintain a good night's sleep. The time to treat warm water on the feet is at night. Because, when the sun starts to darken the pineal gland begins to convert serotonin to the melatonin produced, but instead pumps this hormone directly into the bloodstream. Melatonin will begin to be produced when night falls, which then coordinates body 
functions into a harmonized system [16]. According to [8], soaking in warm water can relieve muscle tension and stimulate the production of brain glands that make the body feel calmer and relaxed. According to [17], warm water soak therapy in the feet can improve blood vessel microcirculation and vasodilation so that it is effectively used to improve the sleep quality of third trimester pregnant women who experience sleep disorders.Soaking warm water on the feet has an impact on sleep quality, which is caused by a feeling of relaxation and increased secretion of the hormone serotonin. Relax conditions arising from soaking warm water on the feet before sleep can reduce the activation of the Reticular Activing System (RAS) which suppresses the activity of the cerebral cortex coupled with increased levels of melatonin. Physiologically in the soles of the feet there are many nerves, especially in the skin, namely Flexusvenosus, from this nerve mechanism the stimulation is transmitted to the posterior horn and then proceed to the spinal cord. This stimulus is continued to enter the brain stem precisely at the bottom of the pons and medulla, this is where the sopartific effect (wanting to sleep) [17].

The opinion above is in accordance with the research data wherein this mechanism is indicated by a decrease in scores on the components of sleep eruption, sleep duration and sleep efficiency. Measurements of 12 respondents, the score of sleep eruption component decreased, which means there was a decrease in sleep eruption from the time range $>60$ minutes to $<30$ minutes. Sleep eruption is the time needed to fall asleep or the time to start sleeping until real sleep.The score of sleep duration component has decreased, which means an increase in the number of hours or duration of sleep. Pregnant women who are given warm water soak therapy on their feet before going to sleep have increased the number of hours of sleep to around 6-8 hours which initially only 3-5 hours. The results of this study are in accordance with the statement of [18] in his research, stating that warm water soak therapy in the feet improves blood vessel microcirculation and vasodilation so that it improves sleep quality with a significance value ( $p$ <.05). Physiologically Regional Bulbar Synchronizing (BSR) takes over and releases serotonin so that respondents will feel sleepy and easy to fall asleep. This situation makes it difficult for the Reticular Activating System (RAS) to be active so that sleep conditions can be maintained [16].

Measurement of sleep efficiency component scores decreased sleep efficiency can be assessed from the total number of hours of sleep divided by the total time of bed, then multiplied by $100 \%$. Sleep efficiency is said to be good if it has a high percentage, in this case the score of the component of sleep efficiency is small. Sleep efficiency increases due to an increase in sleep duration accompanied by reduced sleep eruption 
time. Pregnant women also experience a reduction in the frequency of awakening at night and are easy to fall asleep again. Sleep conditions make the respondents' perceptions of sleep quality improve.The results of this study indicate that there was a statistically significant decrease in sleep quality in third trimester pregnant women after being given warm water soak therapy in the legs of the intervention group and not statistically significant in sleep quality in third trimester pregnant women in the control group.

\section{Conclusion}

The results and discussion that have been presented in the previous chapter, led to the conclusion of this research that is, soaking the feet with warm water has an influence on the sleep quality of trimester III pregnant women where there is an increase in sleep quality in trimester III pregnant women who do soak feet with warm water. This research was conducted in the working area of Cigugur Tengah Health Center in Cimahi City on 24 respondents who were divided into 12 respondents in the intervention group and 12 respondents in the control group. The following are the conclusions of the researchers drawn in this study, namely:

The average sleep quality of third trimester pregnant women before being given therapy in the intervention group was 10.33 (Poor), in the control group was 11.67 (Poor), the average sleep quality of third trimester pregnant women after being given therapy in the intervention group was 5.25 (Poor), in the control group is 11.58 (Poor), there is the effect of warm water soak therapy on the feet to the quality of sleep for the intervention group of third trimester pregnant women in the Cigugur Public Health Center in Cimahi City (Pvalue $\leq \alpha 0.05$ i.e. 0,000 ).

\section{References}

[1] Manuaba, I. B. G.. Science of obstetrics, gynecology and family planning. Jakarta: EGC; 2010.

[2] Sarwono, P. Obstetrics. Jakarta: Yayasan Bina Pustaka Sarwono Prawirohardjo; 2010.

[3] Renityas, N. N., Sari, L. T., \& Wibisono, W.. The effectiveness of acuyoga on insomnia complaints in mother of pregnancy trimester III in traditional agriculture communities in working areas puskesmasnancar current kediri regency. Blitar: Sekolah Tinggi Ilmu Kesehatan Patria Husada; 2017. 
[4] Purwoastuti, E., \& Walyani, E. S.. Guide to reproductive health \& family planning. Yogyakarta: Pustaka baru pres; 2015.

[5] Andari, PA. Quality of sleep and sleep patterns of the third trimester of pregnancy in the Mariati clinic, Medan Marelan sub-district, 2013. Universitas Sumatera Utara; 2013.

[6] Kozier B, et al. Nursing fundamentals: Concept, process, and practice. 2011;2(7).

[7] Arianti, A. The influence of ablution before sleep on sleep quality for third trimester pregnant women at the RBC primary clinic sinergi foundation Bandung. Sekolah Tinggi Ilmu Kesehatan Achmad Yani; 2017.

[8] Sukorini, S. Relationship disorders, physical disorders and diseases with sleep quality mother pregnant trimester III. 2017.

[9] PD. The effect of soaking feet with warm water on anxiety levels in third trimester pregnant women at Pegadon Kendal Public Health Center. Sekolah Tinggi IImu Kesehatan Kendal; 2018.

[10] Istiqomah, Salmiyati. The effect of hydrotherapy with warm foot soak against blood pressure levels in elderly patients with hypertension in Dusun Depik Ambar Ketawang Gamping Sleman. Yogyakarta: Universitas Aisyah Yogyakarta; 2017.

[11] Cimahi DK. Antenatal reports. Cimahi. 2018.

[12] Buysse DJ, Hall ML, Strollo PJ, et al. Relationships between the Pittsburgh Sleep Quality Index (PSQI), Epworth Sleepiness Scale (ESS), and clinical/polysomnographic measures in a community sample. Journal of clinical sleep medicine. 2008;4:563571.

[13] Sihcayanti, N.A. Overview of the quality of sleep and physical symptoms of the pregnant mother in each trimester of pregnancy at the health center, Jetis, Yogyakarta, Indonesia. Gadjah Mada University; 2016.

[14] Suryani P. Exercise, pregnancy and discomfort, pregnant, third trimester. 2018.

[15] Lendetariang $C$. The effect of warm water soaking therapy on feet against insomnia in lansia in Angges Village, West Tahuna District, Manado, Indonesia. Universitas Sam Ratulangi, Manado, Indonesia; 2018.

[16] Potter PA, AGP. Nursing fundamentals. 7th ed. Jakarta: Salemba Medika; 2009.

[17] Martus F. The influence of warm water soak therapy on feet on the quality of sleep of a man in an nursing home in Cibeber, South Cimahi, Cimahi City, Indonesia. Sekolah Tinggi Ilmu Kesehatan Achmad Yani, Indonesia; 2016.

[18] Andriani E, Khotimah H, Supriyadi B. Dukungan keluarga dalam kepatuhan pengobatan pada penderita kusta. 